\title{
HACIA UN ANÁLISIS DEL DESARROLLO TERRITORIAL EN LAS MARISMAS DE LA MARGEN IZQUIERDA DEL GUADALQUIVIR (PÓSTER)
}

\author{
Miguel Ángel Falcón. Universidad Pablo de Olavide (Sevilla, miafasa@ hotmail.com)
}

Resumen

Las Marismas del Guadalquivir constituyeron hasta la segunda mitad del siglo XIX un mayúsculo espacio demográfico semivacío que no tenía un interés más allá de tierras de pasto para el ganado o la práctica de la caza. Para dar respuesta a la agravante situación socioeconómica de la época, se llevaron a cabo proyectos para la desecación de las Marismas del Guadalquivir, que ha llegado hasta hoy como una de las zonas de producción agraria más importantes de Europa.

La situación actual es de elevada dependencia de las políticas agrarias y comerciales del momento, escasa transformación y diversificación de los productos, una población agraria envejecida con escaso relevo generacional...; y basada en una estrategia sin atención a la biodiversidad necesaria para garantizar la supervivencia del espacio como socioecosistema.

La viabilidad futura va a estar condicionada a un modelo de desarrollo rural sostenible con el medio ambiente, y plenamente compatible con una revitalización social y económica del territorio. La investigación va a poner de manifiesto las variables que condicionan el área de estudio y así establecer un análisis y diagnóstico, donde la agricultura va a actuar como eje transversal en cada una de la triple entrada indicada anteriormente para un desarrollo integrado.

Palabras clave: marismas, Guadalquivir, desarrollo, rural, sostenible

\section{Introducción y objetivos}

La idea de investigación surge por la toma de conciencia de la relevancia del territorio estudiado, desde su puesta en valor hace varias décadas atrás, su evolución y la necesidad de adaptarse a las tendencias que marcan las nuevas lógicas socio-económicas y territoriales y así poder garantizar su subsistencia de una forma sostenible y equilibrada con el medio ambiente.

Fruto de los proyectos para la puesta en valor del espacio físico, se ha llegado a un territorio con una estructura económica eminentemente agraria. Aunque en los últimos años ha perdido peso este sector como consecuencia de la globalización, sigue siendo un pilar fundamental que articula el socio-ecosistema.

Por otro lado, las políticas recientes marcan las dinámicas a seguir para garantizar el desarrollo de los espacios territoriales desde una forma integrada en las dimensiones social, ambiental y económica. A nivel mundial destaca la Agenda 2030 para el desarrollo sostenible del año 2015 a través de sus 17 Objetivos de Desarrollo Sostenible (ODS). A nivel continental, el Pacto Verde Europeo 2050 de lucha contra el cambio climático y la nueva Política Agraria Común (PAC) centrada en el ámbito agrario.

El objetivo de la investigación es dar a conocer la relevancia del espacio rural por su origen y trayectoria, no solo a nivel regional y nacional, sino también dentro del marco europeo y fuera del mismo. A partir de este conocimiento se van a poner en relieve las transformaciones necesarias para hacer frente a los requerimientos y demandas que presentan la sociedad actual, fruto del análisis y evaluación de las distintas variables que determinan y caracterizan al territorio estudiado.

\section{1 Ámbito de actuación}

A nivel edafológico, el presente espacio destaca por su planicidad siendo los materiales predominantes de tipo sedimentario muy reciente: limos, arcillas, margas, arenas y gravas. El clima mediterráneo-oceánico es el que caracteriza la zona; la precipitación anual ronda los 500-700 mm, mientras que la temperatura media alcanza los $18^{\circ} \mathrm{C}$, siendo de $27-28^{\circ} \mathrm{C}$ las temperaturas en julio y de $9-10^{\circ} \mathrm{C}$ las de enero. Sin embargo, el cambio climático está provocando unas temperaturas medias más altas en los últimos años, más propias de un clima mediterráneo sub-continental de veranos cálidos.

Las marismas en la margen izquierda del Guadalquivir (MMIG) se encuentran situadas en la provincia de Sevilla y abarcan fundamentalmente a los municipios de Lebrija, Las Cabezas de San Juan y Los Palacios y Villafranca. A los que hay que añadir los poblados creados durante el proceso de colonización y otros que pertenecen a los municipios de Utrera y Dos Hermanas, tal como se indica a continuación: 
Cuadro 1. Mapa de las MMIG

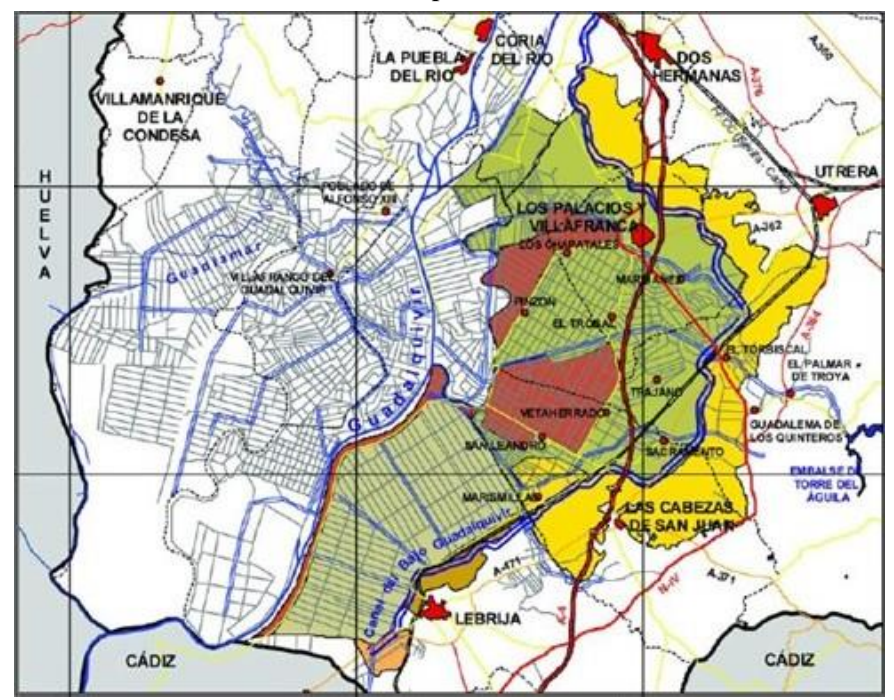

Fuente: Consejería de Agricultura y Pesca: Inventario y Caracterización de regadíos de Andalucía

\section{Metodología}

Para contemplar e integrar la diversidad y las particularidades que conforman el espacio investigado se va a abordar su desarrollo desde un escenario en el que se incluyan las metodologías cuantitativa y cualitativa, de forma que resulten complementarias en aras de tener una concepción más amplia de la realidad del territorio.

En este sentido, se da cabida a las diferentes técnicas e instrumentos de cada diseño metodológico y así afrontar el análisis a través de la aproximación dual que supone la aplicación de las dos perspectivas, para así realizar una investigación integral del socioecosistema actual en los diferentes ámbitos que lo caracterizan.

\subsection{Metodología cuantitativa}

La concepción de desarrollo territorial en las MMIG se va a basar en los tres pilares estratégicos que articulan y cohesionan la comarca, es decir, un modelo de desarrollo rural sostenible con el medio ambiente, y a su vez plenamente compatible con la revitalización social y económica del territorio, donde la agricultura juega un papel crucial como eje transversal positivo en cada una de la triple entrada del desarrollo territorial.

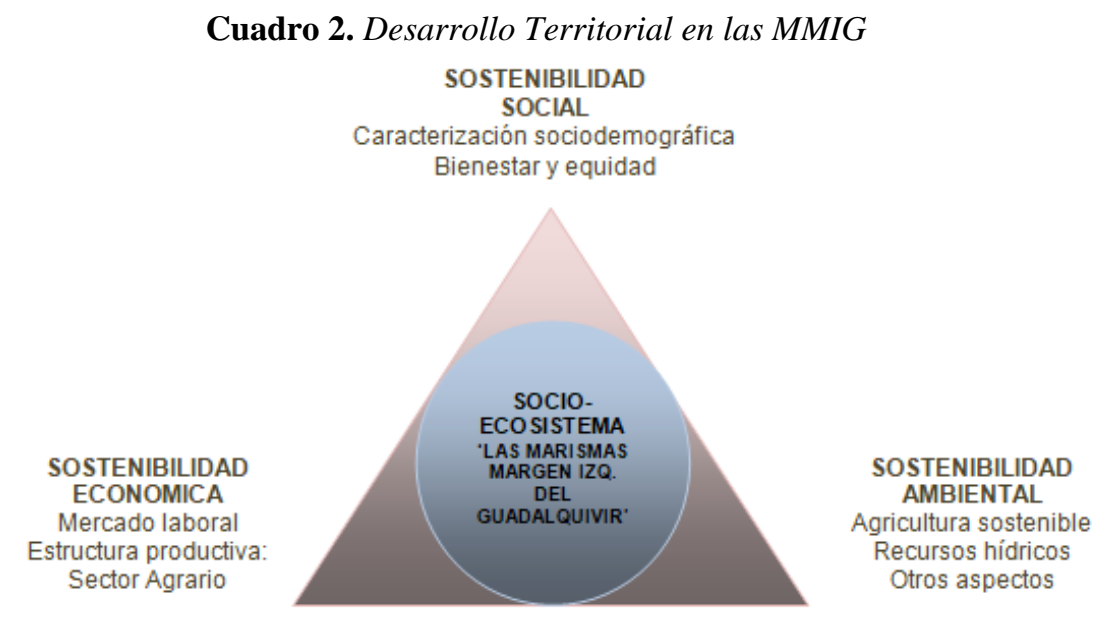

Fuente: Adaptado de Zoido, F. et. A., 2009:250

Para la caracterización de cada uno de los tres vértices del triángulo (en alineación y coherencia con los ODS), se seleccionan las variables con mayor peso e influencia en el territorio, en aras de conocer el grado de desarrollo de las MMIG mediante una comparativa con la situación global de la región (Pita y Pedregal, 2011). 
Asimismo, al ser variables que no son inamovibles en el tiempo, y que dependen de las circunstancias y requerimientos del momento, se establece una observación diacrónica de las mismas. Sin olvidar los antecedentes previos, se va a hacer hincapié en el nuevo milenio por los significativos cambios que afectan al devenir del territorio.

Para el análisis de las mismas se tienen en cuenta los registros estadísticos, así como aquellas otras técnicas de las que se puedan obtener datos cualitativos.

\subsection{Metodología cualitativa}

Se amplía el conocimiento a través de la perspectiva etnográfica para aquellos aspectos a los que no se puede llegar con el análisis anterior.

Fundamentalmente mediante la observación participante de los principales sujetos del desarrollo territorial (colonos y agricultores) y con entrevistas a perfiles técnicos ligados a las políticas y técnicas de la ordenación de las MMIG.

Por último, se realiza la integración de la información obtenida por ambas metodologías, que, aun siendo desde dos enfoques diferenciados, se complementan y enriquecen para unos resultados más completos y fidedignos de la realidad actual del entorno de la investigación.

\section{Primeros resultados y conclusiones}

La comarca que abarca las MMIG presenta un incremento demográfico positivo, por encima de Andalucía y España, por lo que actualmente no existe amenaza de pérdida de población. Ese crecimiento tiene su origen tanto en factores vegetativos, como de inmigración, siendo ambos favorables. Esa dinámica poblacional constituye por tanto una fortaleza para el territorio. En lo que respecta a la población en cuanto a género, los datos generales son bastante similares, ligeramente superior en el caso de las mujeres.

Los datos de renta media declarada suponen una debilidad, pues se encuentran notablemente por debajo de los datos de Andalucía, sin embargo, del mismo modo por encima de la media española.

En lo que respecta a la actividad económica, se muestra una destacada vocación primaria con un porcentaje de superficie agraria muy elevado, específicamente de regadío en las MMIG. Se tratan de explotaciones de tamaño medio, 12 hectáreas en la marisma al inicio de la colonización, pero en los últimos años se ha tendido a la concentración de la tierra por diversos factores como la falta de relevo generacional y la llegada de inversiones ajenas al sector, en una tendencia con la superficie media de explotación en Andalucía (22,7 ha) y con la superficie estatal (25 ha).

Una parte de la producción se concentra en cultivos excedentarios y/o sometidos a la fuerte competencia internacional, en los que la existencia de subvenciones condiciona la actividad (Industriales y cereales, aproximadamente el 80\%). Esos cultivos conviven con producciones hortícolas extensivas más competitivas que se destinan al consumo en fresco y a la transformación, que ha tenido una evolución al alza en los últimos años por su gran rentabilidad y adaptación al espacio rural.

\section{Grafico 1.Cultivos en las MMIG}

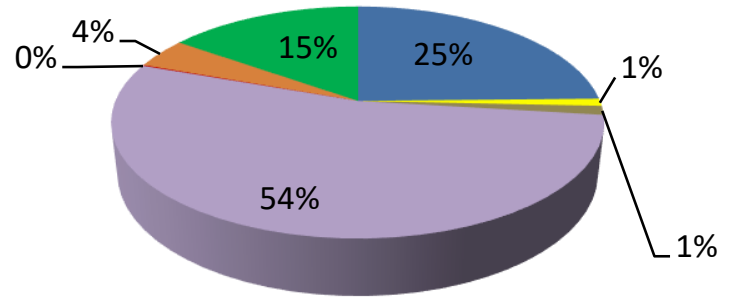

Cereales de invierno
Leguminosas grano
Tubérculos consumo humano
Cultivos industriales
Flores y plantas ornamentales
Cultivos forrajeros
Hortalizas

Fuente: IECA

Sin embargo, no existe una suficiente diversificación productiva, según se pone de manifiesto en el proceso de participación. Y en cuanto a la producción ecológica sigue siendo de escasa relevancia en la comarca.

Se puede extraer una clara tendencia negativa respecto al empleo agrario, donde influyen otros factores claves para el sector, como son las sucesivas reformas de la PAC, y fundamentalmente un cambio de paradigma en la agricultura, con una mayor mecanización y automatización de los procesos agrícolas. Y fundamentalmente la globalización de los mercados, con la ampliación de las zonas cultivables en todo el planeta y a menor coste de producción en la mayoría de los casos. 
Grafico 2.Afiliación a la seguridad social.

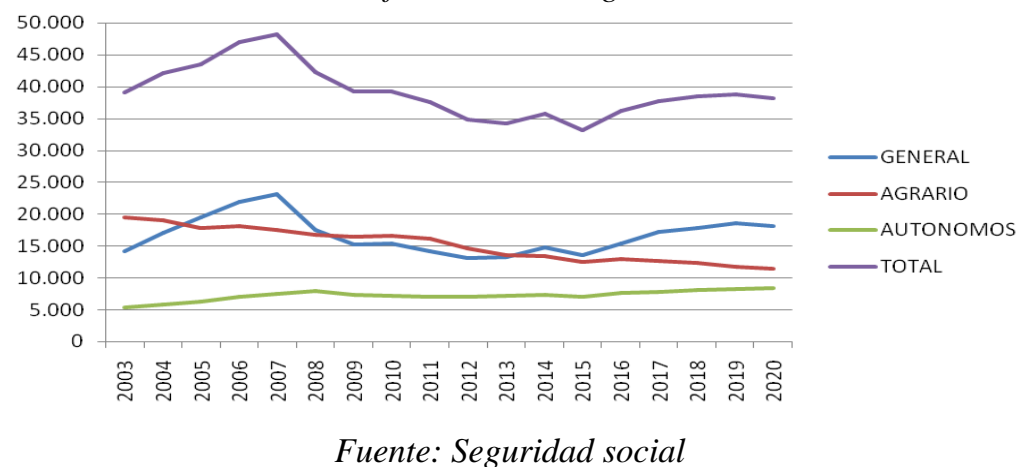

Igualmente, el sector industrial se encuentra fuertemente condicionado por la actividad agraria, lo cual supone una fuente de generación añadido en la comarca, aunque insuficiente. El sector servicios tiene una clara orientación al comercio, siendo el principal empleador de mano de obra femenina. El proceso participativo ha puesto de manifiesto como una debilidad los déficits de formación, cuestión que afecta tanto a los empresarios, como a los trabajadores y a los desempleados. Sin embargo, la actividad productiva tampoco es capaz de generar puestos de trabajo para aquellos jóvenes con mayores niveles de formación, lo que favorece la salida de los mismos de la comarca. Esos déficits formativos pueden estar detrás de los menores niveles de iniciativa empresarial e innovación que se identifican en la comarca.

En general, los ratios de empresas y establecimientos empresariales por cada mil habitantes son desfavorables para la comarca, como también es menor su tamaño en función del empleo, lo que muestra la debilidad relativa del tejido productivo.

\subsection{Conclusiones}

La supervivencia y prosperidad del espacio rural de las MMIG viene determinada por la implantación de una estrategia innovadora en su sentido más extenso, es decir, no sólo centrada en la importante vertiente material (capital natural, productivo y físico-territorial), sino sobre todo a nivel de intangibles (capital humano y social), que se consideran fundamentales para la articulación de todos los procesos de desarrollo, tales como el saber hacer, el espíritu empresarial y de cooperación, etc. (Silva y Moral, 2005, p. 225-226).

Se refiere a diversificación de los cultivos agrícolas, gracias a la disponibilidad de los recursos naturales, especialmente los hídricos, pero con una necesaria optimización de los mismos. Unido a una mayor competitividad a través de un progreso en la transformación de los insumos primarios producidos. Para ello, es clave la formación y la capacitación, fundamentalmente para los jóvenes y las mujeres, arraigando la población al territorio.

\section{Bibliografía}

- Artículos:

Sampedro Sánchez, D.; Abreu Fernández, L.; Guisado Muñiz, A.; Del Moral Ituarte, L.; Pedregal Mateos, B. y Silva Pérez, R. (2005). "Crisis y reestructuración de grandes zonas regables en Andalucía: el caso del Bajo Guadalquivir”. Industria y minería, 361, 26-32

Pita López, M.F. y Pedregal Mateos, B (2011b). "La medición del desarrollo, la cohesión y la diversidad territorial" en Tercer Informe de Desarrollo Territorial de Andalucía (Pita y Pedregal, Coords.). Sevilla. Secretariado de Publicaciones de la Universidad de Sevilla, 307-364.

Silva Perez, R.; Moral Ituarte, L. (2005). "Nuevas dinámicas socioeconómicas y alternativas de desarrollo territorial. El caso de la zona regable del Bajo Guadalquivir". Boletín de la Asociación de Geógrafos Españoles, 223-244.

Silva Pérez, R. (2010). "Multifuncionalidad agraria y territorio. Algunas reflexiones y propuestas de análisis". Revista Latinoamericana de Estudios Urbanos Regionales, 109, 5-33.

- Libros:

Garcia García A. (2013). "El dinamismo socioeconómico de Andalucía. Territorios ganadores y territorios emergentes". Secretariado de publicaciones. Universidad de Sevilla.

Moral Ituarte, L. (1991). "La obra hidráulica en la cuenca baja del Guadalquivir (siglos XVIII-XX). Gestión del agua y organización del territorio". Servicio de Publicaciones de la Universidad de Sevilla, Consejería de Obras Públicas y Transportes, Ministerio de Agricultura, colección KORA. 